\title{
Paradigm Shifting-The Use of Mobile Communications at Work and the Subsequent Effects
}

\author{
Claudiu George Bocean ${ }^{1}$ (D), Silvia Puiu ${ }^{1}$ (D) and Anca Antoaneta Vărzaru ${ }^{2, *(D)}$ \\ 1 Department of Management, Marketing and Business Administration, University of Craiova, \\ 200585 Craiova, Romania; claudiu.bocean@edu.ucv.ro (C.G.B.); silvia.puiu@edu.ucv.ro (S.P.) \\ 2 Department of Economics, Accounting and International Business, University of Craiova, \\ 200585 Craiova, Romania \\ * Correspondence: anca.varzaru@edu.ucv.ro; Tel.: +40-7-7392-1189
}

check for updates

Citation: Bocean, C.G.; Puiu, S.;

Vărzaru, A.A. Paradigm

Shifting-The Use of Mobile Communications at Work and the Subsequent Effects. Electronics 2021,

10, 2747. https://doi.org/electronics 10222747

Academic Editor: Nurul I. Sarkar

Received: 14 October 2021

Accepted: 9 November 2021

Published: 10 November 2021

Publisher's Note: MDPI stays neutral with regard to jurisdictional claims in published maps and institutional affiliations.

Copyright: (c) 2021 by the authors. Licensee MDPI, Basel, Switzerland. This article is an open access article distributed under the terms and conditions of the Creative Commons Attribution (CC BY) license (https:// creativecommons.org/licenses/by/ $4.0 /)$.

\begin{abstract}
The physical distancing measures generated by the COVID-19 pandemic have forced companies to rethink employment patterns and to pay much more attention to the possibility of carrying out work through telework. The expansion of telework, a phenomenon that manifested itself even before the pandemic's health crisis, has gained a particular momentum, changing how work is carried out. The main purpose of this paper is to study the main macroeconomic effects of the accelerated expansion of telework on the economic performance and the employment structure by the economic sectors of the workforce. Using artificial neural network analysis and structured equation modeling, the study highlights the significant influences of telework on economic performance and speeding up the transition service-based economy. The share of teleworkers has a significantly positive influence on economic performance. Moreover, the employees' use of computers, mobile devices, and the internet has a strong mediation effect on the relationship between telework and employment in services. Given these considerations, teleworking is a phenomenon that will become a permanent feature of the future.
\end{abstract}

Keywords: telework; economic performance; employment structure; internet access; mobile communication

\section{Introduction}

Forced and accelerated telework implementation in the context of the COVID-19 pandemic was a necessary practice for many companies and their employees during periods with physical distancing restrictions. This phenomenon significantly impacted companies in all sectors, regardless of past telework experience [1]. Although telework through mobile communication has allowed companies to cope with the crisis better than inexperienced ones, there have also been tensions and problems arising from inequalities through the differentiated access that telework can generate [2].

Telework has been an essential means of maintaining production during the COVID-19 health crisis, but its effects on economic performance are unclear. Bloom et al. [3] show that telework implemented without prior training and without the right working conditions at home can decrease employees' economic performance. In addition, working in inappropriate spaces with children who are involved in online school obviously generates a decrease in individual and collective performance [4]. Although many studies show a decrease in employee performance [5], others, on the contrary, suggest an increase in overall performance due to the time saved by working from home [6].

The sustainable expansion of telework that replaces long-term work in the workplace dramatically increases individual and general performance and other economic and social indicators (employee satisfaction, gender equality, regional inequalities, housing space, and reduction of emissions from means of transport). However, the overall impact of telework can be ambiguous and poses risks, especially in terms of innovation and employee satisfaction resulting from reduced social networking and team spirit. 
Before the health crisis generated by COVID-19, telework experienced varied patterns that differed substantially between countries, sectors, occupations, and firms. Analyzing the differences between countries, economic sectors, professions, and companies concerning telework can help identify the factors that encourage telework implementation. For example, the use of telework has significantly varied between E.U. countries over the past ten years [7]. In addition to the economic structure of countries (i.e., differences in the composition of the economy by economic sectors), other factors can generate these differences, such as culture, use of management practices, digital infrastructure, skills endowment, or the age structure of the workforce [8,9].

This paper proposes highlighting the accelerated spread of telework's main macroeconomic effects on economic performance and employment structure by different economic sectors. The article is structured in six sections. First, after an introduction and review of the literature, we present the research methodology. Next, the research results are shown in the discussions in Sections 4 and 5. Finally, Section 6 concludes and outlines the limits of research and the guidelines for future research.

\section{Literature Review}

\subsection{Defining Teleworking}

The Collins Dictionary [10] defines teleworking as "working from home using equipment such as telephones, fax machines, modems, and mobile devices to contact people" and by the Cambridge Dictionary [11] as "the activity of working at home, while communicating with your office by phone or email, or using the Internet". Both definitions refer to work from home (WFH) using various communication means to maintain contact with colleagues and supervisors. The first question that arises is why from home and not from any place preferred by the employee. Even with some differences, other terms that are frequently used are remote work or work from anywhere (W.F.A.) and telecommuting, the latter implying a previous commute. Global Workplace Analytics [12] uses the term "agile work" for any work done without being physically present at the office.

The first time teleworking appeared was in a book written by Nilles et al. [13], with Nilles being considered the father of this concept. In an interview with Mears [14], Nilles said that it all started in 1973, when they tried to implement this type of work in a pilot program. The result was an increase in productivity by $18 \%$. The obstacles mentioned by Nilles are mainly represented by "inertia" and a "reluctance... to change".

The International Labour Organization [15] (p. 5) uses teleworking, telecommuting, or WFH interchangeably and defines WFH as "a working arrangement in which a worker fulfills the essential responsibilities of his/her job remaining at home, using information communications technology". The report focuses on the importance of WFH, especially during the pandemic, as an important way to reduce the spread of the virus. It also reveals that many employers are worried that their employees do not work as much as when they are at the office. The employees should know the conditions of this work arrangement. Their productivity should be monitored using various indicators but not in a way that might be too intrusive for the employees.

Lister and Harnish [16] conducted a study analyzing telework in the United States of America (U.S.A.). They concluded that most employees in the U.S.A. prefer working from a distance due to the benefits of working away from the office: fewer conflicts, more efficiency, and a more fulfilling life as well as more savings from the money they would have otherwise spent oncommuting. The authors emphasize that for all of these benefits to be real, teleworking should be done correctly, in a combined effort of both partners (employer and employee). Training on this type of work might be a good starting point.

Choudhury et al. [17] analyze the efficiency generated by W.F.A. compared to WFH. The results in terms of productivity favor W.F.A., which grants more flexibility to the employees. According to Messenger and Addati [18] from the International Labour Organization, teleworking offers many more benefits than disadvantages for both the employees and the company. Productivity is the essential indicator that has been noticed to increase 
when offering people this type of flexibility. The authors also highlight that more and more employees can have the opportunity to work from home, such as stay-at-home parents or people with disabilities. Thus, the workplace becomes a more inclusive environment, with teleworking contributing to less discrimination and more diversity.

Eurofound and the International Labour Office [19] highlight the importance of developing national legislation to protect the interests of employers and employees and to contribute to a balanced life. A better solution would be a mixed arrangement that combines teleworking and the traditional means of going to the office. It would provide more benefits in the long term, increasing the employee productivity and satisfaction and reducing the risk of disconnection that can occur when working only from home.

Telework is also influenced by the cultural dimensions of Hofstede [20]. Peters et al. [21] compare the differences in teleworking in two European countries, France and the Netherlands; the authors show that companies should take into account the differences in culture because some countries value more individualism (the Dutch) and thus teleworking, and others focus more on collectivism (the French in authors' comparative study). Adamovic [22] (p. 7) emphasizes the fact that "low power distance or high individualism scores have positive beliefs about telework effectiveness". Peters et al. [21] also showed that France managers valued more power distance and uncertainty avoidance, which decreased the use of teleworking.

Regarding the legal mechanisms used for the implementation of telework, there are also differences among European countries. Eurofound [23] show that there are countries that decided to use a soft law to apply the European Framework Agreement on Telework, which was primarily achieved through guidelines and recommendations; meanwhile, others have used hard law, introducing national laws for telework that make it mandatory for companies to apply their provisions, resulting in teleworking being less common. The European Agency for Safety and Health at Work [24] (pp. 6, 7) classifies countries in two groups, with (Belgium, Bulgaria, Czechia, Spain, Germany, Estonia, France, Greece, Hungary, Croatia, Italy, Lithuania, Luxembourg, Malta, The Netherlands, Poland, Portugal, Romania, Slovenia, and Slovakia) and without "specific legislation" on telework (Austria, Cyprus, Denmark, Finland, Ireland, Latvia, and Sweden).

\subsection{Benefits and Disadvantages of Telework}

Nicholas [25] (p. 9) highlights the benefits offered by teleworking, such as cost savings, as physical offices are limited, greater flexibility for both company and employees, and savings for employees because they will not spend money on transportation or office clothes. The employees will also have a more fulfilling life, with more time with their families because they eat at home and do not commute. As the author mentions, "communications, trust and support" represent "an essential factor of successful teleworking" for these to happen.

The benefits appear at various levels: the employer, the employee, the environment, and the community. Tremblay and Thomsin [26] (p. 110) mention the advantages of not being disturbed by colleagues, more flexibility in when to start and end work daily, time and cost savings, and the possibility for employees investing the time saved by not commuting to work in "personal and professional development." Even with numerous benefits, some companies and employees are not eager to completely exchange traditional work with teleworking. Burton et al. [27] analyze the implications of teleworking and the COVID-19 pandemic (when there was less circulation) on the environment, focusing on the UK's construction sector, which has its challenges when using remote work. The authors appreciate that the technology developments that have taken place in the latest years can contribute to the expansion of telework in more domains nowadays.

The disadvantages that have been mentioned can be seen more as limits or challenges brought by this type of working arrangement. Thus, by changing perspectives, partners can conveniently reach a solution that addresses these challenges. Tavares [28] analyses the effects of teleworking on employee health working remotely and concludes that essential 
health benefits exist. Still, the net result is not well known. Thus, health problems are generated by working too much and not having a clear delimitation of the time frame to work or not having a dedicated space. The author identifies problems such "musculoskeletal problems, isolation, deprivation, stress, and overwork" [28] (p. 33). Furthermore, long-term teleworking is not for everyone. Some employees are more friendly and prefer working among their colleagues or having a designated time and space for work, creating boundaries between their professional and personal lives.

Gimenez-Nadal et al. [29] conducted research to compare teleworkers and commuters regarding time spent to work, work timing, and the pleasure felt when working. They concluded that teleworkers work less, and because they are more flexible with their schedule, they do not have fixed working hours. As a result, teleworkers are more engaged in leisure activities or personal chores than commuters in the middle of the day. Having this freedom, teleworkers (especially men) are happier when they are teleworking than their colleagues who are working at the office. Bentley et al. [30] highlight the importance of organizational support in offering better working conditions of teleworkers and increasing the outcomes of telework.

Boll et al. [31] analyzed the role played by technology in teleworking. This working model can use technology to benefit employees and their employers with proper guidance and training. The authors mainly focus on teamwork and the need to interact with their colleagues when clarifying certain questions. Collaborative work is essential and can boost creativity in many domains, so teleworkers should use technology to contact their peers to maintain a climate that stimulates innovative ideas even when working remotely.

The COVID-19 pandemic proved the importance of telework and efficiency in reducing the spread of the virus and in reducing traffic, thus protecting the environment by contributing to pollution reduction, especially in major cities worldwide. However, a European Commission report [32] states that the evolution of teleworking from 2009 to 2019 was relatively slow. Only $5.4 \%$ of the employees usually have this arrangement, with significant differences being found between the member states. In countries such as Sweden, Finland, and the Netherlands, the share of the employees working from home was usually more than $30 \%$; meanwhile, in most E.U. countries, the percentage was less than $10 \%$. The need to send the employees home during the lockdown raised the challenge of training employees to have the competencies to work remotely. Digital skills are a requirement in these conditions. As the European Commission [32] (p. 1) states, "half of the workers... had no prior experience with teleworking", making them more vulnerable and maybe even prone to losing their jobs.

Regarding the impact of teleworking on the environment, this way of working can reduce emissions and mitigate climate change. Giovanis [33] (p. 12) appreciates that "teleworking can be a viable short- and long-term solution to emissions, fuel consumption, and traffic congestion reduction". Hook et al. [34] (p. 27) also conducted a similar analysis regarding the impact of teleworking on the environment that concluded that "teleworking has some potential to reduce energy consumption and associated emissions". Graham and Marvin [35] (p. 252) see "telecommuting as an environmental policy" that when implemented in such, can reduce carbon dioxide emissions and protect the environment.

A report from the UNDP [36] (p. 7, 10) analyzing teleworking during the pandemic concludes that this work arrangement if used "on a large scale", can contribute to "lower carbon emissions". Liu et al. [37] analyzed data regarding global emissions in the first half of 2020, when most countries in the world were in lockdown and showed a decrease of $8.8 \%$ compared with the previous year. According to Carbon Monitor [38], global emissions in 2020 compared to those from 2019 decreased by 4.4\%, with differences between countries and regions being notable: China had an increase of $0.5 \%$, U.S.A. a decrease of $12.5 \%$, the EU-27 and United Kingdom experienced a reduction of 7.5\%, Japan a saw reduction of 5\%, Russia saw a reduction of $2.9 \%$, and Brazil saw a decrease of $9.8 \%$.

Harpaz [39] and Deloitte [40] summarized the benefits and challenges of telework on three levels: employers, employees, and society (Table 1). 
Table 1. Benefits and disadvantages of telework.

\begin{tabular}{|c|c|c|}
\hline & Benefits & Challenges \\
\hline Employers & $\begin{array}{l}\text { Removing geographical barriers to work allows talent to be attracted; } \\
\text { Reduction of absenteeism due to a minor illness; } \\
\text { Business resilience in emergency cases, such as natural disasters, } \\
\text { epidemic threats, transport strikes, or adverse weather conditions; } \\
\text { Increased productivity due to a more appropriate homework } \\
\text { environment, the freedom to work comfortably, and reduced exposure } \\
\text { to company policy; } \\
\text { Savings of housing space and facilities of the company; }\end{array}$ & $\begin{array}{l}\text { Lack of adequate information and } \\
\text { communications technology (I.C.T.) } \\
\text { infrastructure; } \\
\text { Higher costs with tracksuits and } \\
\text { equipment for those working remotely; } \\
\text { A weaker organizational culture; } \\
\text { The security of I.T. systems and } \\
\text { sensitive business information; }\end{array}$ \\
\hline Employees & $\begin{array}{l}\text { Cost savings by eliminating transport costs and reducing the cost of } \\
\text { clothing or food; } \\
\text { Improving work-life balance; } \\
\text { Increased labor satisfaction; } \\
\text { Increased participation (allows rural employees, people with } \\
\text { disabilities, employees in less developed countries to access better jobs); } \\
\text { Location flexibility; }\end{array}$ & $\begin{array}{l}\text { Exclusion from decisions at work; } \\
\text { Lack of technical assistance from the } \\
\text { specialized department; } \\
\text { Isolation of their peers; } \\
\text { "Blurring roles" between work and } \\
\text { personal life leading to extra work; }\end{array}$ \\
\hline Society & $\begin{array}{l}\text { Reducing traffic congestion and transport infrastructure demand; } \\
\text { Regional development through relocations outside major cities; } \\
\text { Reducing electricity and fossil fuel consumption used in transport. }\end{array}$ & $\begin{array}{l}\text { Risk of having individuals who may } \\
\text { lack social skills. }\end{array}$ \\
\hline
\end{tabular}

Source: Adapted from Harpaz [39] and Deloitte [40].

\subsection{The Relationship between Telework and Performance}

Numerous studies show a direct connection between teleworking and performance $[17,18,39,41-45]$. According to Fujii [44], telework can increase employee productivity, which can be seen as motivation. Bloom [45] conducted a study on a company and determined that teleworkers in call centers made "13.5\% more calls" than their peers at the office, and also the company also saved "USD 1900 per employee for the nine months".

Thorstensson [46] argues that many factors influence teleworker productivity. Thus, even if most studies show a positive impact, the extent of the effect depends on factors such as the technology and the equipment available for the personnel who are working from home and the employee attitudes towards this type of work arrangement. The author also highlights the fact that productivity is also dependent on the context. For example, some teleworkers can have lower productivity in times of crisis, such as during the pandemic, due to the imposed self-isolation.

Despite all of these benefits, telework has been banned by some important companies in recent years [47-49], making this decision using the argument that collaborative work is critical, thus ignoring the new realities and attracting criticism from the people affected by these decisions (the Yahoo C.E.O. Marissa Mayer in 2013, the attempt of B.N.Y. Mellon in 2019, I.B.M. in 2017 with their campaign Move or Leave). Furthermore, the COVID-19 pandemic made 21 crucial companies reconsider their work arrangements, thus allowing their employees to work remotely in the long term [50].

However, not all jobs permit remote patterns. Madgavkar and Lund [51] appreciate that only $20 \%$ of developed countries can work from home without a problem. Still, this work arrangement is impossible to implement in sectors such agriculture, production, or services requiring direct contact between the parties involved. The authors also highlight that some hospitality industry businesses might suffer when most workers are at home.

\section{Materials and Methods}

To study the main macroeconomic effects of the accelerated expansion of telework on the economic performance and the employment structure by economic sectors of the workforce, we used the indicators collected from the Eurostat database $[7,52-55]$ as macroeconomic variables: the share of the teleworkers in the total number of jobs (T.W.), the gross domestic product per capita (GDPC), employment in services (E.I.S.), employment in industry (E.I.I.), employment in agriculture (E.I.A.), the use of computers and mobile 
devices for internet by employees (UCIE), and enterprises with internet access (I.A.). The sample includes data collected for the 27 countries belonging to the European Union from the last ten years (2010-2019).

The share of teleworkers in the total number of jobs (T.W.) is a variable that illustrates the percentage of employees who are engaged in telework in total employment annual information collected by Eurostat based on the European Union Labor Force Survey. Variable gross domestic product per capita (GDPC), which can be used at the macroeconomic level to illustrate the economic performance, represents the value of all goods and services that produced less than intermediate consumption. Our research used an index of G.D.P. per capita expressed in relation to the European Union average set to equal 100 [52]. The data for the use of computers and the internet by employees (UCIE) and for enterprises with internet access (I.A.) represents the percentage of total respondents and includes annual information collected by Eurostat based on questionnaires determining I.C.T. usage in enterprises $[53,54]$. The variables employment in services (E.I.S.), employment in industry (E.I.I.), and employment in agriculture (E.I.A.) describe the employment structure based on the European Commission study Employment and Social Developments in Europe [55].

Starting from a literature review and our own observations, we formulated three hypotheses concerning the relationships between the variables that we investigated:

Hypothesis 1 (H1). The share of teleworkers (T.W.) has a significant positive on economic performance (GDPC).

Hypothesis 2 (H2). The economic sector significantly differentiates the teleworker share (T.W.) on employment structure (E.I.S., E.I.I., and E.I.A.).

Hypothesis 3 (H3). The extent of the use of computers and mobile devices for the internet by the employees (UCIE) and the internet access of enterprises (I.A.) strongly mediates the relationship between telework (T.W.) and employment in services (E.I.S.).

We used inferential statistical and mathematical methods to validate the research hypotheses: curve estimation regression, artificial neural networks analysis, and structural equation modeling. The curve estimation regression procedure offers statistic regression and afferent graphics for nine different linear and non-linear regression models to identify the most appropriate model to use. To test the validity of hypotheses $\mathrm{H} 1$ and $\mathrm{H} 2$, we applied artificial neural networks analysis. We obtain linear and non-linear relationships starting from the input variables depending on the input and output variables. A non-linear activation function processed the results. The most used activation functions were the sigmoid (1) and the hyperbolic tangent (2).

$$
\begin{gathered}
f(n)=\frac{1}{1+e^{-n}}=\frac{e^{n}}{e^{n}+1} \\
f(n)=\frac{e^{n}-e^{-n}}{e^{n}+e^{-n}}=\frac{e^{2 n}-1}{e^{2 n}+1}
\end{gathered}
$$

$\mathrm{n}$-input variable;

$\mathrm{f}(\mathrm{n})$ - output variable.

We used these functions because they are close to the linear functions and allow nonlinear modeling in order to achieve the proximity of saturation. Additionally, to validate the $\mathrm{H} 1$ and the $\mathrm{H} 2$ hypotheses, we calculated the correlations to triangulate the data.

To determine the validity of hypothesis $\mathrm{H} 3$, we used structural equation modeling [56]. The formula for structural equation modeling is:

$$
\eta=\mathrm{B \eta}+\Gamma \xi+\zeta
$$


$\eta$-vector of latent endogenous variables;

$\xi$-vector of latent exogenous variables;

$\mathrm{B}$-matrix of regression coefficients which report latent endogenous variables;

$\Gamma$-matrix of regression coefficients regarding exogenous variables;

$\zeta$-vector of perturbation conditions.

Structural equation modeling is used to test substantive theories, which infers some observable and latent variables $[57,58]$. Latent variables cannot be measured directly by a visible variable, making it necessary to consider structural equation modeling.

\section{Results}

To test the validity of the H1 hypothesis, we used curve estimation regression from SPSS v.20. The variable illustrating teleworking (T.W.) was considered an independent variable; meanwhile, the variable showing the economic performance (GDPC) was deemed dependent. Table 2 and Figure 1 show the nine different linear and non-linear regression models that were tested to identify the appropriate model to further our research.

Table 2. Testing linear and non-linear functions for the variables telework (T.W.) and economic performance (GDPC).

\begin{tabular}{|c|c|c|c|c|c|c|c|}
\hline \multirow{2}{*}{ Equation } & \multicolumn{5}{|c|}{ Summary of the Model } & \multirow{2}{*}{ Constant } & \multirow{2}{*}{ b1 } \\
\hline & R Square & $\mathbf{F}$ & df1 & df2 & Sig. & & \\
\hline Linear & 0.452 & 229.361 & 1 & 278 & 0.000 & 58.441 & 7.928 \\
\hline Logarithmic & 0.358 & 154.927 & 1 & 278 & 0.000 & 62.297 & 27.922 \\
\hline Inverse & 0.156 & 51.208 & 1 & 278 & 0.000 & 110.588 & -23.776 \\
\hline Composition & 0.520 & 300.789 & 1 & 278 & 0.000 & 64.140 & 1.074 \\
\hline Power & 0.503 & 281.861 & 1 & 278 & 0.000 & 64.052 & 0.279 \\
\hline S & 0.280 & 107.980 & 1 & 278 & 0.000 & 4.657 & -0.269 \\
\hline Growth & 0.520 & 300.789 & 1 & 278 & 0.000 & 4.161 & 0.072 \\
\hline Exponential & 0.520 & 300.789 & 1 & 278 & 0.000 & 64.140 & 0.072 \\
\hline Logistic & 0.520 & 300.789 & 1 & 278 & 0.000 & 0.016 & 0.931 \\
\hline
\end{tabular}

Source: Developed by the authors based on data calculated with SPSS.

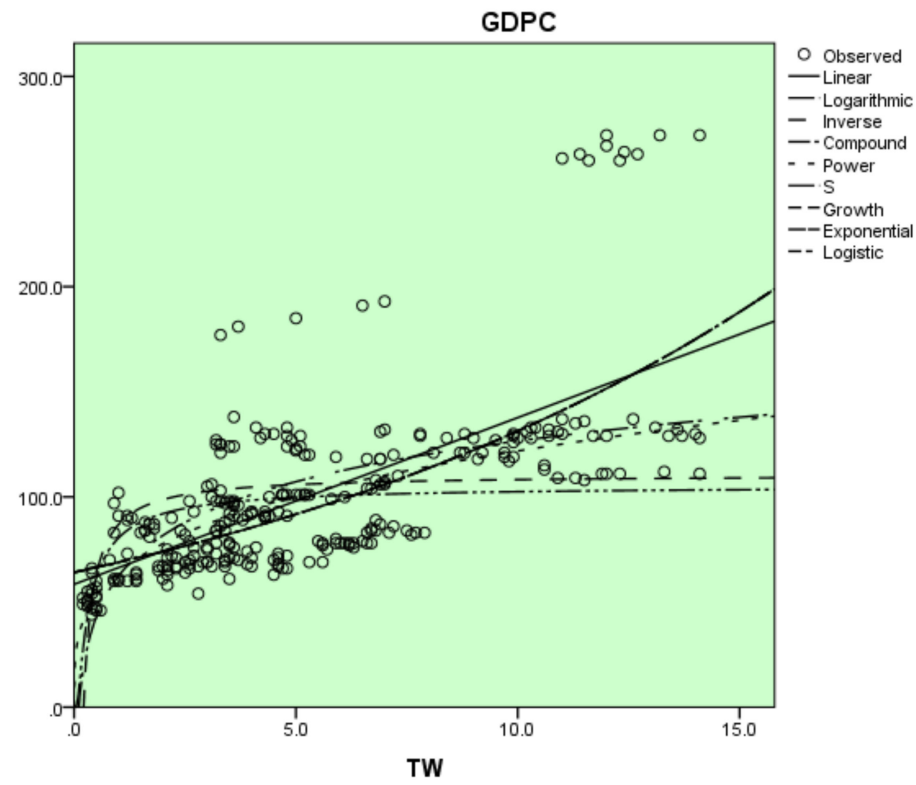

Figure 1. The curve estimation regression of economic performance (GDPC) depending on the telework (T.W.). Source: Developed by the authors based on the calculated data in SPSS.

From the analysis of the values registered by the functions tested in Table 2 and the graphic illustration in Figure 1, we noticed that the optimal function was the logistic sigmoid function. Based on function testing, we extended our investigation by analyzing the 
artificial neural network. We used T.W. as an input variable and GDPC as an output variable to determine the effects of the accelerated spread of telework on economic performance.

The estimated parameters of the M.L.P. model are described in Table 3. The model used a single hidden layer and generated a single unit of the layer's influence. We assumed that the level of technological development represents a hidden layer.

Table 3. The values of the multilayer perceptron model concerning telework (T.W.) and economic performance (GDPC).

\begin{tabular}{cccc}
\hline \multirow{2}{*}{ Predictor } & & \multicolumn{2}{c}{ Predicted Values } \\
\cline { 3 - 4 } & & Hidden Layer 1 & Output Layer \\
\cline { 3 - 4 } & & H(1:1) & GDPC \\
\hline \multirow{2}{*}{ Entry layer } & (Bias) & 0.012 & - \\
& TW & -1.028 & - \\
Hidden layer & (Bias) & - & 0.035 \\
& H(1:1) & - & -2.533 \\
\hline
\end{tabular}

Source: Developed by the authors based on data calculated with SPSS.

Figure 2 illustrates the relationships among the variables.

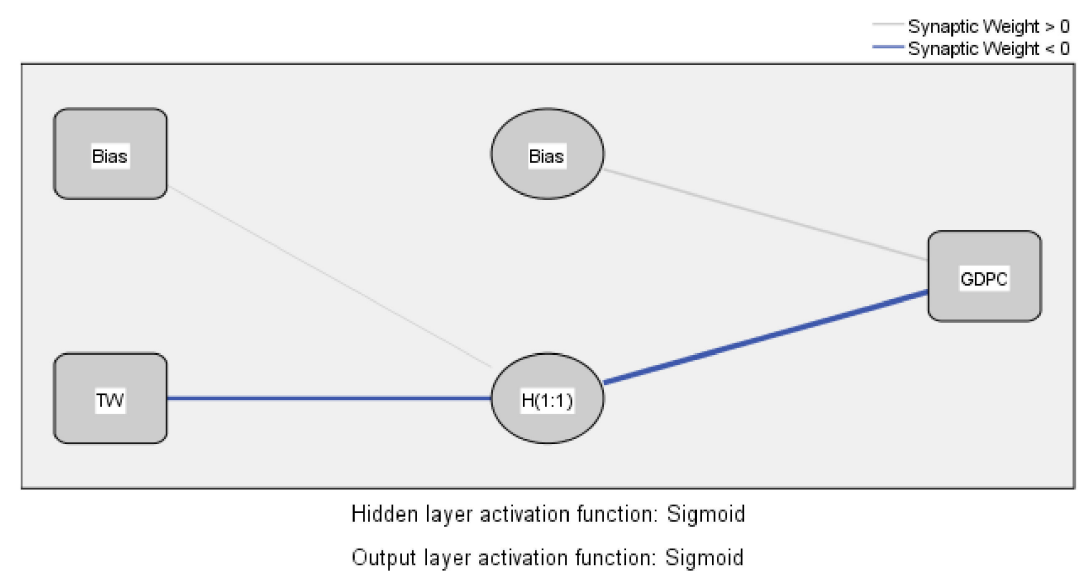

Figure 2. The multilayer perceptron model to identify the influences of telework (T.W.) on the economic performance (GDPC). Source: Developed by the authors using SPSS. Note: Bias-the influences of the exogenous factors; T.W.—-telework; GDPC—economic performance; $\mathrm{H}(1: 1)$-the unit of the hidden layer.

The artificial neural network analysis that was established between the input layer defined by T.W. and the output layer defined by GDPC illustrates a directly proportional strong effect that is exercised by telework on economic performance and that is amplified by each country's technological level development.

After researching the artificial neural network established between the studied variables, we can conclude that there is a proven correlation of direct proportionality between telework on the one hand and economic performance on the other hand, which means that hypothesis $\mathrm{H} 1$ is valid. Furthermore, the share of teleworkers (T.W.) has a significantly positive influence on economic performance (GDPC), as shown by other studies $[17,18,43,44,59]$.

To research the validity of the hypothesis $\mathrm{H} 2$, we also used the analysis of the artificial neural network, in which we used T.W. as an input variable and E.I.S., E.I.I., E.I.A. as output variables to determine the effects of the accelerated spread of telework on employment by different economic sectors.

Table 4 presents the estimated parameters of the multilayer perceptron (M.L.P.) model. We used a single hidden layer, and the model generated a single unit of the hidden layer. We assumed the substitution level of physical jobs with telework depending on the economic sector representing a hidden layer. 
Table 4. The values of the multilayer perceptron model concerning telework (T.W.) and employment by sectors (E.I.S., E.I.I., E.I.A.).

\begin{tabular}{|c|c|c|c|c|c|}
\hline \multirow{2}{*}{\multicolumn{2}{|c|}{ Predictor }} & \multicolumn{4}{|c|}{ Predicted Values } \\
\hline & & \multirow{2}{*}{$\begin{array}{c}\text { Hidden Layer } 1 \\
\text { H(1:1) }\end{array}$} & \multicolumn{3}{|c|}{ Output Layer } \\
\hline & & & EIS & EII & EIA \\
\hline \multirow{2}{*}{ Entry layer } & (Bias) & 0.599 & - & - & - \\
\hline & TW & 0.631 & - & - & - \\
\hline \multirow{2}{*}{ Hidden layer } & (Bias) & - & 0.003 & -2.437 & -0.905 \\
\hline & $\mathrm{H}(1: 1)$ & - & 0.963 & -0.115 & -1.777 \\
\hline
\end{tabular}

Source: Developed by the authors based on the data calculated with SPSS.

Figure 3 shows the relationships between the variables.

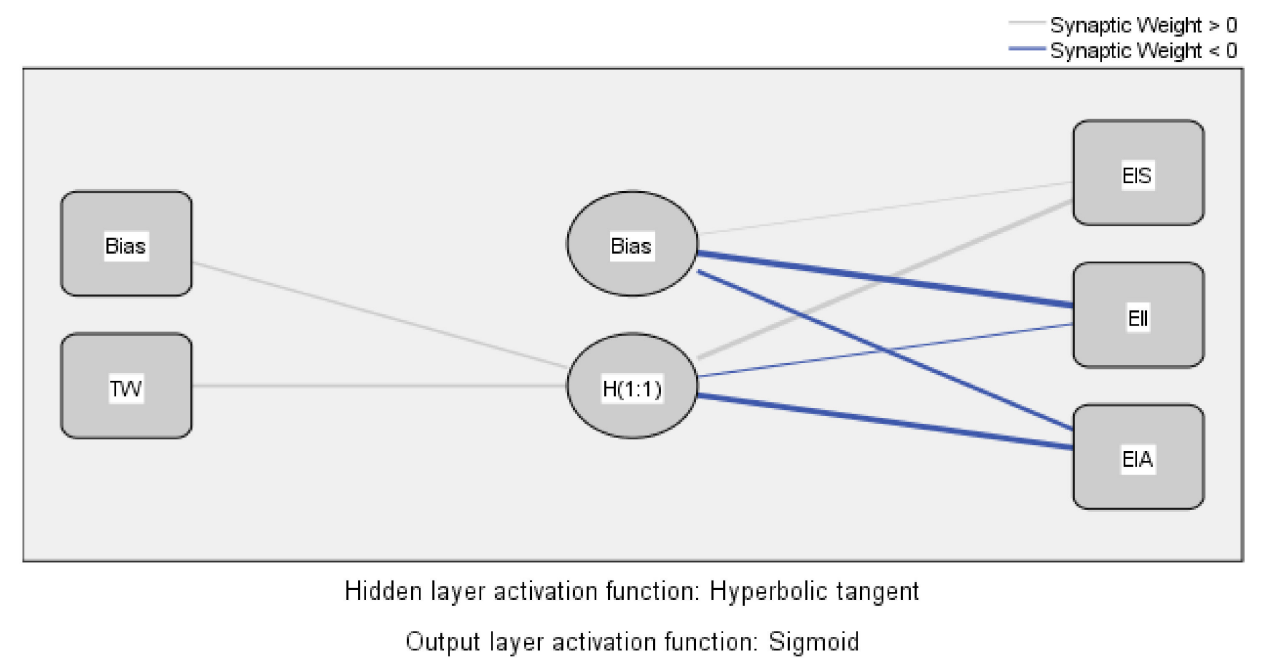

Figure 3. Multilayer perceptron model to identify the influences of telework (T.W.) on the employment by sectors. Source: Developed by the authors based on the data calculated with SPSS. Note: Bias-the influences of the exogenous factors; T.W.—telework; E.I.S.-employment in services; E.I.I.-employment in the industry; E.I.A.—employment in agriculture; $\mathrm{H}(1: 1)$ - the unit of the hidden layer.

The analysis of the artificial neural network established between the input layer defined by T.W. and the output layer defined by the employment in services (E.I.S.), employment in industry (E.I.I.), and employment in agriculture (E.I.A.) illustrates a directly proportional strong effect exerted by telework on employment in services and an inversely proportional impact on E.I.I. and E.I.A.

After researching the artificial neural network between the studied variables, we can conclude that telework can be tailored to some activities, especially in services, and less to agriculture and industry. In these sectors, automatization has substituted or can substitute almost the entire workforce. This fact allows us to state that hypothesis $\mathrm{H} 2$ hypothesis is valid. The influences of the teleworker share (T.W.) on the employment by different sectors (E.I.S., E.I.I., E.I.A.) are significantly different depending on the economic sector. The results are similar to other studies [1,60].

To research the validity of hypothesis $\mathrm{H} 3$ and to identify the mediation effect of the variables, the use of computers and mobile devices for internet by the employees (UCIE), and the internet access of enterprises (I.A.), we used the model of the structural equations established between telework and the employment in services (E.I.S.). Figure 4 illustrates the diagram of the relationships among the variables. The selected model defines three observable variables (E.I.S., UCIE, and I.A.) as endogenous variables and with T.W. being the visible exogenous variable. In addition, the model includes three attached unobservable exogenous variables (i1, i2, p1) that influence each endogenous variable. 


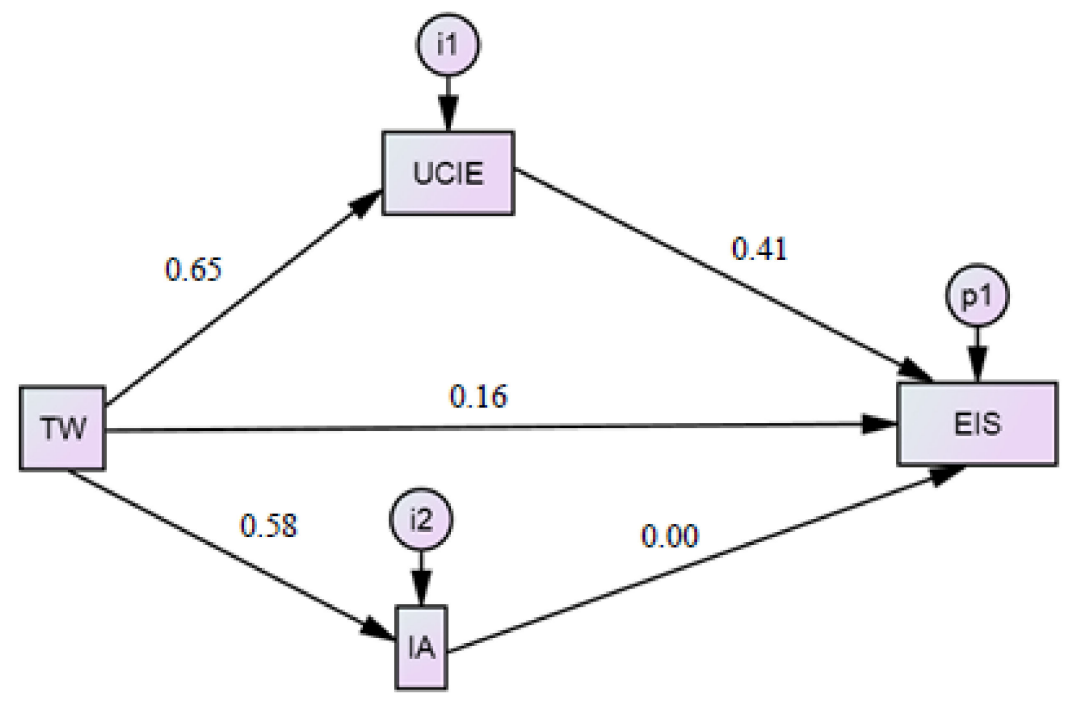

Figure 4. The diagram of the relationships in structural equation modeling. Source: Developed by the authors using AMOS for SPSS. Note: T.W.—telework; E.I.S.-employment in services; UCIEuse of computers and internet by the employees; I.A.--internet access of enterprises; i1, i2, p1unobservable exogenous variables.

The follow method was used to estimate the likelihood, and to register an adequate level of significance: Chi-square $\chi 2=55.763, \mathrm{df}=1, p=0.000<0.05$. The non-normed fit index (NNFI) and the comparative fit index (CFI) registered values the 0.966 and 0.969 , respectively, both of which are above 0.90 , showing good significance. Table 5 presents the direct, indirect, and total effects that were registered between the model variables.

Table 5. The standardized effects registered between the variables of the structural equations modeling.

\begin{tabular}{|c|c|c|c|c|c|c|c|c|c|c|c|}
\hline \multicolumn{4}{|c|}{ Standardized Total Effects } & \multicolumn{4}{|c|}{ Standardized Direct Effects } & \multicolumn{4}{|c|}{ Standardized Indirect Effects } \\
\hline & T.W. & I.A. & UCIE & & T.W. & I.A. & UCIE & & T.W. & I.A. & UCIE \\
\hline I.A. & 0.670 & 0.000 & 0.000 & I.A. & 0.581 & 0.000 & 0.000 & I.A. & 0.000 & 0.000 & 0.000 \\
\hline UCIE & 2.215 & 0.000 & 0.000 & UCIE & 0.654 & 0.000 & 0.000 & UCIE & 0.000 & 0.000 & 0.000 \\
\hline E.I.S. & 1.093 & -0.003 & 0.307 & E.I.S. & 0.162 & -0.002 & 0.406 & E.I.S. & 0.265 & 0.000 & 0.000 \\
\hline
\end{tabular}

Source: Developed by the authors using AMOS for SPSS. Note: T.W.—-telework; E.I.S.-employment in services; UCIE—use of computers and internet by the employees; I.A.-internet access of enterprises.

After analyzing Figure 4 and Table 5, we observed a strong mediation effect of UCIE and a less significant mediation effect of I.A. because this variable records values close to the maximum in almost all E.U. countries.

Synthetizing the research results, the hypothesis $\mathrm{H} 3$ is partially validated. The use of computers and mobile devices to access the internet by the employees (UCIE) has a strong mediation effect on the relationship between telework and employment in services (E.I.S.); meanwhile, the internet access of enterprises (I.A.) does not have a significant influence. The research results are in line with the results of other studies [61-65].

\section{Discussion}

The first research led us to conclude that the teleworker share has a significantly positive influence on economic performance (expressed at the macroeconomic level by G.D.P. per capita), as shown by other studies [17,18,43,44]. As the percentage of teleworkers increases, the marginal added value is higher, positively affecting economic performance. Regarding the causality relationship between T.W. and performance, Gschwind and Vargas [59] appreciate that it is difficult to identify, considering that the variables that arise in T.W. are numerous. The authors mention the effect on the health of teleworkers; T.W. requires teleworkers to be highly skilled in technology in the long run. Additionally, they conclude that T.W. in Europe has different characteristics depending on the country's level 
of development, both economic and technological, and the country's culture t influences employee and employer attitudes towards T.W.

The second research direction led us to conclude that the teleworker share (T.W.) in terms of employment by sector (E.I.S., E.I.I., E.I.A.) is significantly different and depends on the economic sector. Additionally, OECD [1] mentions the differences in the share of teleworkers in various sectors of the economy: a high percentage of T.W. characterizes the I.T. sector; meanwhile, the production, retail industry, transportation, healthcare, social services, hospitality industries do not provide such flexibility to employees because they require a physical presence or direct contact with the customer. Eurofound [60] (p. 9) presents the sectors with a higher share of teleworkers (I.C.T. sector, scientific domain, finance, real estate, public administration) and highlights that all of these sectors have "a high level of I.C.T. dependency" in common.

The third research direction led us to conclude that the use of computers, mobile devices, and the internet by employees has a strong mediation effect on the relationship between telework and employment in services; meanwhile, the internet access of enterprises does not have a significant influence. Baloh and Trkman [61] analyze the impact of using the internet on human resources management, from recruiting employees to motivating, controlling, or implementing new working methods such as teleworking. The authors conclude that using the internet creates many advantages for both the employees and the employers. Finally, Tate et al. [62] explored the relationship between computer-mediated communication (C.M.C.) and using the internet on employee engagement in teleworking. The authors concluded that C.M.C. factors (attentiveness, expressiveness, and motivation) positively impact the engagement level of teleworks.

Lopez-Igual and Rodriguez-Modrono [63] studied the factors that impact telework and information and communication technology-based mobile work. They concluded that education level, jobs requiring higher qualifications, age, gender, and living in rural or urban areas strongly influence teleworking. Ruiz-Martinez and Esparcia [64] also analyzed the impact of internet access on telework and e-commerce in rural areas of Spain and concluded that the lack of adequate infrastructure can adversely affect them, highlighting local the role of local authorities in ensuring sufficient infrastructure. Lewis [65] researched the impact of I.C.T. on telework in public administration in France. The author concluded that the technical problems and the lack of or inappropriate support for dealing with such issues negatively affect the activities of teleworkers and the activities of their colleagues who are working in the office. The connection between technology and telework is strong. Still, the efficiency depends on teleworkers' skills and abilities when facing technical problems (weak internet connection, lack of a dedicated hotline for receiving support, lack of equipment, devices, and software related to work at home).

The acceleration of telework implementation through mobile communication will generate more essential benefits for the economy. Increasing labor participation will improve economic performance, particularly in groups that disadvantaged by the spatial restrictions of certain jobs (rural employees, people with disabilities, and employees from less developed countries). This is why governments have a strong political motivation to support telework implementation through infrastructure investments (including 5G internet networks). Even without an increase in labor participation, telework offers the benefits of improving performance across the economy. These occur through the time savings incurred through telework deployment, reallocating the time used for mobility at work to productive time. Overall, this phenomenon will increase economic growth, even if there are the same number of workers. In addition, saving on public expenditure on transport infrastructure due to its use at a lower level, with no need for new investment and maintenance of existing capacities, can be created as well.

The crisis generated by COVID-19 has forced organizations to use telework through mobile communication on a large scale to ensure the continuity of some activities, especially in the service sector. Even after most countries have progressively suspended physical distancing measures, which will allow all employees to return to their offices, 2020 and 2021 
will undeniably represent a significant turning point in the long-term expansion of telework. These years will have substantial implications for the service sector in particular and will have a positive influence on overall economic performance.

\section{Conclusions}

Telework has existed for years, but it was not widespread until 2020 even though the expansion of new technologies has dramatically reduced the cost of implementing flexible work arrangements based on telework. The crisis generated by COVID-19, physical distancing measures, and associated quarantines have forced many organizations to look for ways to operate, at least in part, in full remote mode. Many employers and employees believe that the advantages of telework outweigh the disadvantages, paving the way to spread this practice. Several recent studies have attempted to quantify the pace of telework through mobile communication and to describe the consequences for employees $[8,66-68]$.

\subsection{Empirical Implications}

The practical implications of our empirical research conducted at the European Union member state-level allowed us to state that teleworking expansion has a significant favorable influence on economic performance (expressed at the macroeconomic level by G.D.P. per capita). An increase in the percentage of teleworkers positively influences economic performance, with the marginal added value being higher. Secondly, the impacts of teleworking expansion on employment by sectors is differentiated significantly depending on the economic sector, specifically for services in sectors in which telework can successfully substitute physical jobs. Following our research, we found that the employees' use of computers and mobile devices for internet access is a variable that strongly mediates the relationship between telework and employment due to the e digital skills the employees, which allow them more easily engage in telework.

\subsection{Theoretical Implications}

Based on the research, we were able to determine critical policies that are relevant to the area of telework. How telework can influence economic performance and employment patterns and structure depends on the presence of policies that are able to maximize economic benefits. First, where appropriate, policies should ensure that telework remains a choice in order to prevent remote work from being over-used. Physical communication is essential, especially for complex tasks and innovation [69]. Secondly, policies should encourage mechanisms that provide workers with the proper working environment to provide I.C.T. equipment, stable connections, engaging workspaces, or childcare facilities. Worker satisfaction and, ultimately, the economic performance of organizations may also decrease to the extent that some of the costs of telework are not accepted by businesses but are transferred to employees (more expensive housing, higher electricity bills, high childcare costs) $[70,71]$. Thirdly, policies should facilitate the implementation of best practices as a result of telework expansion. Managers need to adapt to the opportunities and challenges posed by telework. Reducing direct supervision will cause managers to abandon presenteeism and move towards a performance culture [19]. Managers must also adapt and not disrupt employees through excessive checks, taking up productive time with virtual supervisory meetings.

Finally, labor encouragement policies must make it easier for businesses and employees to access computers and the internet. The availability of I.C.T. infrastructure is an essential prerequisite for facilitating the expansion of telework, and its quality influences the economic performance achieved as a result of telework. Therefore, it takes effective means of communication (including the possibility of video conferencing), which require reliable and fast internet connections [1,72,73].

In addition to improving economic performance, policies that facilitate telework expansion also provide benefits in ensuring gender equality, enhancing employment opportunities in rural areas, reducing road traffic, reducing carbon emissions, reducing house 
costs in urban areas, and a better work-life balance. Relevant policies supporting telework expansion cover three main areas: supporting infrastructure investment, supporting overcoming cultural and legal obstacles, and mitigating potential side effects [1].

Stimulating investment in communications infrastructure to encourage businesses to implement telework requires the accelerated deployment of fibers in the broadband service networks of internet providers in order to increase the capacity and resilience of communications infrastructure [1] and to help reduce regional disparities [74].

Promoting global telework and combating social and regional disparities can be achieved by stimulating investment in relevant skills, especially among employees who do not have the necessary skills that are required by telework. Promoting online education is appropriate in order to provide training opportunities for potential employees in rural areas or who are from another national culture [75]. A cultural change can be achieved through information campaigns on good practice models and highlighting benefits beyond economic performance, such as reducing environmental impact and improving worklife balance. Telework implementation through mobile communication within the sector could lead to its de-bureaucratization. The legal system must adapt to overcome the legal obstacles presented by telework [76].

To mitigate potential side effects, such as innovation scarcity due to reduced interactivity, companies can create virtual workspaces that can stimulate innovation, thus reducing road and rail traffic and reducing regional inequalities $[75,77]$. Other side effects relate to extended overtime work, which can be combated by an employee's right to disconnect, or privacy issues that additional data protection regulations can address to ensure employee privacy rights.

\subsection{Limitations and Further Research}

As a limitation of our research, it is worth mentioning that the research was conducted at the macroeconomic level and did not present the perceptions of teleworkers. Additionally, the study was conducted using data collected at the European level, meaning that the results that are provided here are specific to European culture. There are also significant differences across European countries in terms of the cultural aspects of telework. Diverse approaches to telework have been adopted among different European countries, which is likely due to the fact that labor legislation is still unharmonized at the European level. Another limitation, the lack of COVID-19 pandemic period analysis, can be determined by the scarcity of the data. Future research must have a hybrid approach (macro-micro level) to analyze teleworking from a dual perspective to capture the complexity of this type of work arrangement by taking into account the cultural aspects of this phenomenon and new developments caused by the COVID-19 pandemic.

Author Contributions: All three authors equally contributed to designing and writing this paper. Conceptualization, C.G.B., S.P. and A.A.V.; methodology, C.G.B.; software, C.G.B.; validation, C.G.B., S.P. and A.A.V.; formal analysis, S.P.; investigation, C.G.B., S.P. and A.A.V.; resources, S.P. and A.A.V.; data curation, C.G.B.; writing — original draft preparation, C.G.B., S.P. and A.A.V.; writing-review and editing, C.G.B., S.P. and A.A.V.; visualization, A.A.V.; supervision, S.P.; project administration, A.A.V. All authors have read and agreed to the published version of the manuscript.

Funding: This research received no external funding.

Data Availability Statement: Data can be found at following websites: Eurostat, https://ec.europa. eu/eurostat/databrowser/view/lfsa_ehomp/default/table?lang=en; Eurostat, https: / / ec.europa. eu/eurostat/databrowser/view/tec00114/default/table?lang=en; Eurostat, http:/ /appsso.eurostat. ec.europa.eu/nui/show.do?dataset=isoc_ci_cm_pn2\&lang=en; Eurostat, https://appsso.eurostat. ec.europa.eu/nui/submitViewTableAction.do; European Comission, https:/ /op.europa.eu/en/ publication-detail/-/ publication/e823d46f-e518-11eb-a1a5-01aa75ed71a1/language-en.

Conflicts of Interest: The authors declare no conflict of interest. 


\section{References}

1. OECD. Productivity Gains from Teleworking in the Post-COVID-19 Era: How Can Public Policies Make It Happen? OECD Policy Responses to Coronavirus (COVID-19). 2020. Available online: https:/ /www.oecd.org/coronavirus/policy-responses/ productivity-gains-from-teleworking-in-the-post-covid-19-era-a5d52e99/ (accessed on 15 April 2021).

2. Brussevich, M.; Dabla-Norris, E.; Khalid, S. Who Will Bear the Brunt of Lockdown Policies? Evidence from Tele-Workability Measures Across Countries; IMF Working Paper, No. W.P./20/88; International Monetary Fund: Washington, DC, USA, 2020.

3. Bloom, N.; Liang, J.; Roberts, J.; Ying, Z.J. Does Working from Home Work? Evidence from a Chinese Experiment. Q. J. Econ. 2015, 122, 1351-1408. [CrossRef]

4. Gorlick, A. The Productivity Pitfalls of Working from Home in the Age of COVID-19. Stanford News, 2020. Available online: https:/ / news.stanford.edu/2020/03/30/productivity-pitfalls-working-home-age-covid-19/ (accessed on 4 May 2021).

5. Morikawa, M. COVID-19, Teleworking, and Productivity. 2020. Available online: https://voxeu.org/article/covid-19-teleworkingand-productivity (accessed on 1 April 2021).

6. Ozimek, A. The Future of Remote Work. Upwork, 2020. Available online: https://www.upwork.com/press/economics/thefuture-of-remote-work/ (accessed on 7 April 2021).

7. Eurostat. Employed Persons Working from Home as a Percentage of the Total Employment, by Sex, Age, and Professional Status (\%). 2020. Available online: https://ec.europa.eu/eurostat/databrowser/view/lfsa_ehomp/default/table?lang=en (accessed on 1 April 2021).

8. Dingel, J.I.; Neiman, B. How many jobs can be done at home? Natl. Bur. Econ. Res. 2020. [CrossRef]

9. Boeri, T.; Caiumi, A.; Paccagnella, M. Mitigating the work-safety trade-off. Covid Econ. Vetted Real-Time Pap. 2020, 1, 60-66.

10. Collins Dictionary. Definition of Teleworking. n.d. Available online: www.collinsdictionary.com/dictionary/english/teleworking (accessed on 27 April 2021).

11. Cambridge Dictionary. Meaning of Teleworking. n.d. Available online: https://dictionary.cambridge.org/dictionary/english/ teleworking (accessed on 27 April 2021).

12. Global Workplace Analytics. Why Agile Work? n.d. Available online: https://globalworkplaceanalytics.com/purpose (accessed on 28 April 2021).

13. Nilles, J.M.; Carlson, F.R.; Gray, P. The Telecommunications-Transportation Tradeoff: Options for Tomorrow; Wiley Publishing Inc.: London, UK, 1976.

14. Mears, J. Father of Telecommuting Jack Nilles Says Security, Managing Remote Workers Remain Big Hurdles. 2007. Available online: https:/ / www.networkworld.com/article/2299251/father-of-telecommuting-jack-nilles-says-security--managingremote-workers-remain-big-hurd.html (accessed on 30 April 2021).

15. International Labour Organization. An Employers' Guide on Working from Home in Response to the Outbreak of COVID-19. 2020. Available online: www.ilo.org/wcmsp5/groups/public/---ed_dialogue/---act_emp/documents/publication/wcms_745024.pdf (accessed on 26 April 2021).

16. Lister, K.; Harnish, T. Telework and its effects in the United States. In Telework in the 21st Century; Messenger, J., Ed.; Edward Elgar Publishing: Cheltenham, UK, 2019; pp. 128-170.

17. Choudhury, P.R.; Foroughi, C.; Larson, B. Work-from-anywhere: The productivity effects of geographic flexibility. Strateg. Manag. J. 2020, 42, 1-29. [CrossRef]

18. Messenger, J.; Addati, L. Teleworking: The Strong Case for Working Remotely. 2013. Available online: www.ilo.org/global/ about-the-ilo/newsroom/news/WCMS_208067/lang--en/index.htm (accessed on 28 April 2021).

19. Eurofound and the International Labour Office. Working Anytime, Anywhere: The Effects on the World of Work; Publications Office of the European Union: Luxembourg; International Labour Office: Geneva, Switzerland, 2017. Available online: www. ilo.org/wcmsp5/groups/public/---dgreports/---dcomm/---publ/documents/publication/wcms_544138.pdf (accessed on 28 May 2021).

20. Hofstede, G. Culture's Consequences: Comparing Values, Behaviors, Institutions, and Organizations Across Nations, 2nd ed.; Sage: Thousand Oaks, CA, USA, 2001.

21. Peters, P.; Bleijenbergh, I.; Oldenkamp, E. Cultural sources of variance in telework adoption in two subsidiaries of an ICTmultinational. Int. J. Employ. Stud. 2009, 17, 66-101.

22. Adamovic, M. How does employee cultural background influence the effects of telework on job stress? The roles of power distance, individualism, and beliefs about telework. Int. J. Inf. Manag. 2022, 62, 102437. [CrossRef]

23. Eurofound. Telework in the European Union. 2010. Available online: https://www.eurofound.europa.eu/sites/default/files/ef_ files/docs / eiro/tn0910050s/tn0910050s.pdf (accessed on 30 October 2021).

24. European Agency for Safety and Health at Work. Regulating Telework in a Post-COVID-19 Europe. Available online: https: / / euagenda.eu/upload/publications/telework--20post-covid.pdf (accessed on 30 October 2021).

25. Nicholas, A.J. Management and Telework. Faculty and Staff-Articles E Papers, 2016. Available online: http:/ / digitalcommons. salve.edu/fac_staff_pub/60 (accessed on 29 April 2021).

26. Tremblay, D.G.; Thomsin, L. Telework and mobile working: Analysis of its benefits and drawbacks. Int. J. Work. Innov. 2012, 1, 100-113. Available online: https:/ / core.ac.uk/download/pdf/35146847.pdf (accessed on 29 April 2021). [CrossRef]

27. Burton, E.; Edwards, D.J.; Roberts, C.; Chileshe, N.; Lai, J.H.K. Delineating the Implications of Dispersing Teams and Teleworking in an Agile UK Construction Sector. Sustainability 2021, 13, 9981. [CrossRef] 
28. Tavares, A.I. Telework and health effects review. Int. J. Healthc. 2017, 3, 30-36. [CrossRef]

29. Gimenez-Nadal, J.I.; Molina, J.A.; Velilla, J. Telework, the Timing of Work, and Instantaneous Well-Being: Evidence from Time Use Data; Institute of Labour Economics: Bonn, Germany, 2018.

30. Bentley, T.A.; Teo, S.T.T.; McLeod, L.; Tan, F.; Bosua, R.; Gloet, M. The role of organisational support in teleworker wellbeing: A socio-technical systems approach. Appl. Ergon. 2016, 52, 207-215. [CrossRef]

31. Böll, S.; Cecez-Kecmanovic, D.; Campbell, J. Telework and the Nature of Work: An Assessment of Different Aspects of Work and the Role of Technology. In Proceedings of the European Conference on Information Systems (ECIS), Tel Aviv, Israel, 9-11 June 2014; Available online: http:/ / aisel.aisnet.org/ecis2014/proceedings/track01/16 (accessed on 30 April 2021).

32. European Commission. Telework in the E.U. before and after the COVID-19: Where We Were, Where We Head to. 2020. Available online: https:/ / ec.europa.eu/jrc/sites/jrcsh/files/jrc120945_policy_brief_-_covid_and_telework_final.pdf (accessed on 30 April 2021).

33. Giovanis, E. The relationship between teleworking, traffic and air pollution. Atmos. Pollut. Res. 2018, 9, 1-14. [CrossRef]

34. Hook, A.; Court, V.; Sovacool, B.K.; Sorrell, S. A systematic review of the energy and climate impact of teleworking. Environ. Res. Lett. 2020, 15, 093003. Available online: https://iopscience.iop.org/article/10.1088/1748-9326/ab8a84 (accessed on 28 April 2021). [CrossRef]

35. Graham, S.; Marvin, S. Telecommunications and the City: Electronic Spaces, Urban Places; Routledge: London, UK, 1996.

36. UNDP. How We Worked from Home. Report Prepared by UNDP Accelerator Lab Malaysia; United Nations Development Programme: Putrajaya, Malaysia, 2020.

37. Liu, Z.; Ciais, P.; Deng, Z.; Lei, R.; Davis, S.J.; Feng, S.; Zheng, B.; Cui, D.; Dou, X.; Zhu, B.; et al. Near-real-time monitoring of global $\mathrm{CO}_{2}$ emissions reveals the effects of the COVID-19 pandemic. Nat. Commun. 2020,11, 1-12. [CrossRef]

38. Carbon Monitor. Carbon Emissions Variation. Data Release. 2021. Available online: https://carbonmonitor.org/ (accessed on 30 April 2021).

39. Harpaz, I. Advantages and disadvantages of telecommuting for the individual, organization and society. Work Study 2002, 51, 74-80. [CrossRef]

40. Deloitte. Next Generation Telework: A Literature Review; Australian Government Department of Broadband, Communications and the Digital Economy: Canberra, Australia, 2011.

41. Sánchez, A.M.; Pérez Pérez, M.; de Luis Carnicer, P.; José Vela Jiménez, M. Teleworking and workplace flexibility: A study of impact on firm performance. Pers. Rev. 2007, 36, 42-64. [CrossRef]

42. Arling, P. The Impact of Telework on Performance: A Social Network Approach. In Proceedings of the 10th Americas Conference on Information Systems, New York, NY, USA, 6-8 August 2004.

43. Bhattacharya, S.; Mittal, P. The Impact of Individual Needs on Employee Performance while Teleworking. Australas. Account. Bus. Financ. J. 2020, 14, 65-85. [CrossRef]

44. Fujii, K. Workplace Motivation: Addressing Telework as a Mechanism for Maintaining Employee Productivity. Bachelor's Thesis, Portland State University, Portland, OR, USA, May 2020. [CrossRef]

45. Bloom, N. To Raise Productivity, Let More Employees Work from Home. Harvard Business Review, April 2014. Available online: https:/ / hbr.org/2014/01/to-raise-productivity-let-more-employees-work-from-home (accessed on 3 May 2021).

46. Thorstensson, E. The Influence of Working from Home on Employees' Productivity: Comparative Document Analysis between the Years 2000 and 2019-2020; Informatik B-Thesis, Karlstad Business School, Karlstad University: Karlstad, Sweden, 2020.

47. Arthur, C. Yahoo Chief Bans Working from Home. The Guardian, 2013. Available online: https://www.theguardian.com/ technology/2013/feb/25/yahoo-chief-bans-working-home (accessed on 7 May 2021).

48. McCulloch, A. Major Bank Reverses Its Working from Home Ban. Personnel Today, 2019. Available online: https://www. personneltoday.com/hr/major-bank-u-turn-on-working-from-home-ban/ (accessed on 1 April 2021).

49. Asay, M. Why Companies That Ban Remote Work Hurt Only Themselves; TechRepublic: San Francisco, CA, USA, 2019. Available online: https://www.techrepublic.com/article/why-companies-that-ban-remote-work-hurt-only-themselves/ (accessed on 1 April 2021).

50. Hadden, J.; Casado, L.; Sonnemaker, T.; Borden, T. 21 Major Companies that Have Announced Employees Can Work Remotely Long-Term; Business Insider: New York, NY, USA, 2020. Available online: https:/ /www.businessinsider.com/companies-asking-employeesto-work-from-home-due-to-coronavirus-2020 (accessed on 4 May 2021).

51. Madgavkar, A.; Lund, S. Remote Working Is Here to Stay. But Who Will Be Doing It? 2020. Available online: https:/ www weforum.org/agenda/2020/12/remote-working-who-will-be-doing-it/ (accessed on 31 May 2021).

52. Eurostat. G.D.P. per Capita in P.P.S. 2020. Available online: https://ec.europa.eu/eurostat/databrowser/view/tec00114/default/ table?lang=en (accessed on 4 April 2021).

53. Eurostat. Use of Computers and the Internet by Employees. 2020. Available online: http:/ /appsso.eurostat.ec.europa.eu/nui/ show.do?dataset=isoc_ci_cm_pn2\&lang=en (accessed on 2 April 2021).

54. Eurostat. Internet Access. 2020. Available online: https://appsso.eurostat.ec.europa.eu/nui/submitViewTableAction.do (accessed on 4 April 2021).

55. European Commission. Employment and Social Developments in Europe. 2020. Available online: https://op.europa.eu/en/ publication-detail/- / publication/e823d46f-e518-11eb-a1a5-01aa75ed71a1/language-en (accessed on 21 April 2021). 
56. Kaplan, D. Structural Equation Modelling. In International Encyclopedia of the Social E Behavioral Sciences; Smelser, N.J., Baltes, P.B., Eds.; Pergamon: İzmir, Turkey, 2001; pp. 15215-15222.

57. Hu, L.-T.; Bentler, P.M. Fit indices in covariance structure modeling: Sensitivity to underparameterized model misspecification. Psychol. Methods 1998, 3, 424-453. [CrossRef]

58. Sinharay, S. An Overview of Statistics in Education. In International Encyclopedia of Education; Peterson, P., Baker, E., McGaw, B., Eds.; Elsevier: Amsterdam, The Netherlands, 2010; pp. 1-11.

59. Gschwind, L.; Vargas, O. Telework and its effects in Europe. In Telework in the 21st Century; Messenger, J., Ed.; Edward Elgar Publishing: Cheltenham, UK, 2019; pp. 36-75.

60. Eurofound. Telework and ICT-Based Mobile Work: Flexible Working in the Digital Age; New Forms of Employment Series; Publications Office of the European Union: Luxembourg, 2020.

61. Baloh, P.; Trkman, P. Influence of Internet and Information Technology on Work and Human Resource Management. Proc. Inf. Sci. 2003, 497-506. Available online: https:/ / proceedings.informingscience.org/IS2003Proceedings/docs/071Baloh.pdf (accessed on 8 April 2021).

62. Tate, T.D.; Lartey, F.M.; Randall, P.M. Relationship between Computer-Mediated Communication and Employee Engagement among Telecommuting Knowledge Workers. J. Hum. Resour. Sustain. Stud. 2019, 7, 328-347. [CrossRef]

63. Lopez-Igual, P.; Rodriguez-Modrono, P. Who is Teleworking and Where from? Exploring the Main Determinants of Telework in Europe. Sustainability 2020, 12, 8797. [CrossRef]

64. Ruiz-Martínez, I.; Esparcia, J. Internet Access in Rural Areas: Brake or Stimulus as Post-COVID-19 Opportunity? Sustainability 2020, 12, 9619. [CrossRef]

65. Lewis, R.A. The Influence of Information Technology on Telework: The Experiences of Teleworkers and Their Non-Teleworking Colleagues in a French Public Administration. Int. J. Inf. Educ. Technol. 2013, 3, 32-35. [CrossRef]

66. Gottlieb, C.; Grobovsek, J.; Poschke, M. Working from home across countries. Covid Econ. 2020, 8, 71-91.

67. Hensvik, L.; Le Barbanchon, T.; Rathelot, R. Which Jobs Are Done from Home? Evidence from the American Time Use Survey. I.Z.A. Discussion Paper Series. 2020, IZA DP No. 13138. Available online: https://www.iza.org/publications/dp/13138/whichjobs-are-done-from-home-evidence-from-the-american-time-use-survey (accessed on 3 April 2021).

68. Mongey, S.; Weinberg, A. Characteristics of Workers in Low Work-from-Home and High Personal-Proximity Occupations; White Paper; Becker Friedman Institute for Economics: Chicago, IL, USA, 2020. Available online: https://bfi.uchicago.edu/wp-content/ uploads/BFI_White-Paper_Mongey_3.2020.pdf (accessed on 1 April 2021).

69. Grundke, R.; Marcolin, L.; Nguyen, L.B.; Squicciarini, M. Which Skills for the Digital Era? Returns to Skills Analysis, OECD Science, Technology and Industry Working Papers, No. 2018/09; OECD Publishing: Paris, France, 2018. [CrossRef]

70. Donadio, R. The Coming Setback for Women in the Workplace. 2020. Available online: https://www.theatlantic.com/international/ archive/2020/05/france-women-workplace-coronavirus-pandemic/612136/ (accessed on 4 April 2021).

71. Alon, T.; Doepke, M.; Olmstead-Rumsey, J.; Tertilt, M. The Impact of COVID-19 on Gender Equality. NBER Working Paper, No. 26947. 2020. Available online: http:/ / www.nber.org/papers/w26947 (accessed on 3 April 2021).

72. Andrews, D.; Nicoletti, G.; Timiliotis, C. Digital Technology Diffusion: A Matter of Capabilities, Incentives or Both? OECD Economics Department Working Papers, No. 26947; OECD Publishing: Paris, France, 2018. [CrossRef]

73. Bajgar, M.; Calligarisi, S.; Calvinoi, F.; Criscuoloi, C.; Timmisi, J. Bits and Bolts: The Digital Transformation and Manufacturing; OECD Science, Technology and Industry Working Papers, No. 2019/01; OECD Publishing: Paris, France, 2019. [CrossRef]

74. De Stefano, T.; Kneller, R.; Timmis, J. The (Fuzzy) Digital Divide: The Effect of Broadband Internet Use on U.K. Firm Performance; University of Nottingham, Department of Economics: Nottingham, UK, 2014. Available online: https:/ / www.nottingham.ac.uk/ economics/documents/discussion-papers/14-06.pdf (accessed on 23 April 2021).

75. Clancy, M. The Case for Remote Work; Economics Working Papers, No. 20007; Iowa State University, Department of Economics: Ames, IA, USA, 2020. Available online: https:/ /lib.dr.iastate.edu/econ_workingpapers/102 (accessed on 5 April 2021).

76. Atkinson, R.; Brake, D.; Castro, D.; Ezell, S. Digital Policy for Physical Distancing: 28 Stimulus Proposals That Will Pay Long-Term Dividends. Information Technology \& Innovation Foundation. 2020. Available online: https://itif.org/publications/2020/04/06 / digital-policy-physical-distancing-28-stimulus-proposals-will-pay-long-term (accessed on 3 April 2021).

77. Tanasie, A.; Dracea, R.; Ladaru, G.R. A Chaos Theory Perspective on International Migration. Sustainability 2017, 9, 2355. [CrossRef] 